\title{
Leg Pain
}

National Cancer Institute

\section{Source}

National Cancer Institute. Leg Pain. NCI Thesaurus. Code C34764.

A sensation of discomfort emanating from the femur or its supporting structures. 